Geology Today, 2015, 31(5), 187-192

\title{
Enhanced visualization of the flat landscape of the Cambridgeshire Fenlands
}

Oliver Pritchard*, Timothy Farewell and Stephen Hallett.

School of Energy, Environment and Agrifood, Cranfield University, Cranfield, Bedfordshire, MK43 OAL.

\section{${ }^{*}$ Corresponding Author: Oliver Pritchard}

School of Energy, Environment and Agrifood, Cranfield University, Cranfield, Bedfordshire, MK43 OAL.

Email: oliver.pritchard@cranfield.ac.uk

\section{Summary}

The fenlands of East Anglia represent a subtle landscape, where topographic highs rarely exceed $30 \mathrm{~m}$ above sea level. However, the fens represent an almost full sequence of Quaternary deposits, together with islands of Cretaceous and Jurassic outcrops, making the area of geological importance. This feature discusses the advantages of using 3D visualisation coupled with high-resolution topographic data, over traditional 2D techniques, when undertaking an analysis of the landscape. Conclusions suggest that the use of 3D visualisation will result in a higher level of engagement, particularly when communicating geological information to those outside academia.

\section{Introduction}

The East Anglian Fenlands have been described by some as a flat, unpromising wilderness. On one hand, the fenland area is extremely low-lying with extensive swathes of land actually below sea level and where topographic 'highs' struggle to reach $30 \mathrm{~m}$ above sea level (Figure 1). However, geologically, the Fenlands provide us with an almost complete sequence of Quaternary superficial deposits. Coupled with outcrops or islands of Jurassic and Cretaceous strata (e.g. the Isle of Ely), these deposits give the area its national geological and scientific importance.

Whilst traditional two-dimensional (2D) mapping of the area has revealed much of the complex geological and geomorphological history, the increasing availability of three-dimensional (3D) visualisation software to the earth scientist has resulted in a new dimension (pardon the pun) to geological and landscape interpretation. This feature discusses the use of 3D visualisation 
techniques, coupled with high-resolution topographical, geological and soils data in providing an interactive approach to interpreting the complex and subtle fenland landscape.

We were inspired to write this article after a recent demonstration of the value of using the 3D visualisation software, Geovisionary from Virtalis Ltd. in disseminating landscape models for selected areas of the East Anglian Fenlands at the Cambridgeshire Geology Club's seminar 'The Geology and Landscape of the Fen Edge', held in September, 2014. This demonstration received both an engaging and encouraging response from both the specialist and non-specialist alike, with attendees enjoying plenty of interaction with the visualisation system. Therefore, we suggest here that 3D-visualisation techniques can help further engage and develop discussions between actors including stakeholders, interested public and scientific communities alike, regarding not only the landscape evolution of the Fenlands of East Anglia, but ultimately also those across the UK.

\section{3D Visualisation}

The Geovisionary system itself spawned from a 3-year research collaboration between the virtual reality company, Virtalis and the British Geological Survey (BGS), who had originally sought the means to portray and interact with their own extensive geoscience data banks. The Geovisionary software allows the user to display a range of environmental, geological and other geospatial data within a 3D environment, and contains a limited set of landscape feature interpretation tools such as the terrain measurement and profile tool (Figure 2). The system is immersive, allowing users to don 3D glasses and move 'into the data' in a very visually compelling way. It has particular appeal when disseminating and analysing both geological, soils and other environmental information portraying very well the 'fusing' of these datasets as a coherent whole. Geovisionary sets itself apart from other established 3D software, in that it allows the interactive digitisation of features into 3D space, especially important in a geological context.

However, what Geovisionary has offered us in this instance is a new technique to evaluate the landscape of the Fenlands. The semi-portable nature of the particular 'ActiveMove' system we have also means that disseminating the 3D models can be achieved with ease from most locations. Videos can also be produced using the software, allowing modelled 3D landscapes to be viewed over the web (i.e. YouTube) and to large numbers of people when engaging in a spoken talk or lecture environment (e.g. http://www.youtube.com/watch?v=Ak4j1pJEk0A). 
Through our experiences as a site-based engineering geologist and an academic geologist / soil scientist, we are acutely aware of the importance of fieldwork in understanding a landscape. However, when interpreting landscape at a regional-scale it can sometimes prove difficult to visualise in-the-field per se. This is due to the presence of buildings, infrastructure, crops and trees which often obscure landscape features. In contrast, Geovisionary provides the user with an unmasked view of the entire landscape, showing this to a high resolution where appropriate data is used. Geovisionary can therefore act as a supporting tool for the identification of specific areas of geological and geomorphological interest, helping the user in locating sites requiring further field studies.

Although not approached within this feature, Geovisionary also allows the user to represent a 3D view of the subsurface; where, for example, borehole logs and bedrock fence diagrams can be imported. This allows the viewer to 'fly' below the ground surface, providing a 3D interpretation of the subsurface. This provides a more interactive appreciation of subsurface geology than currently represented by 2D ground models.

\section{Topographic Data}

Both bedrock and superficial geology exert an important influence on topography. Subsequently, topography and geological parent material control the spatial distribution of soils (excepting glacial mass movements). Slope changes and breaks often reflect geological influence. For example, varying slopes could represent the relative erodibility of underlying bedrock formations, the activity of previous glaciations, be suggestive to the location of river terraces, or indeed represent landforms resulting from human activity (e.g. archaeology, infrastructure embankments, landfill etc.). The United Kingdom (UK) is fortunate in that it has access to a wealth of topographic data, available through a range of sources, aimed at both the open-source and commercial markets. However, this article draws particular attention to those data-sources which are either openly-available or are made available free of charge for research and non-commercial purposes.

The Ordnance Survey (OS) has produced several topographic datasets, derived from their base mapping. The coarser of these are the earlier Panorama and more recent Terrain 50 datasets, which both have a 50m horizontal resolution and are publicly available for download (see: www.ordnancesurvey.co.uk/opendatadownload/products.html). The OS also have a commercially available dataset, Terrain 5, representative of a $5 \mathrm{~m}$ horizontal resolution. Problematically however, 
the open-source datasets provided by the Ordnance Survey do not allow for an appreciation of the subtle geomorphological landforms present in the fens, especially with Terrain 50's (and Panorama's) inherent $4 \mathrm{~m}$ vertical accuracy. Fenland landforms are often extremely subtle in their appearance, with sometimes as little as $10 \mathrm{~cm}$ 's variation in height (Figure 5). Therefore, higher-resolution topographic data are required for detailed landscape analysis.

A source of high-resolution topographic data in the UK, with the incentivising offering of a $100 \%$ discount for non-commercial and research purposes, is LiDAR (Light detection and ranging) data provided by the Environment Agency's (EA) Geomatics group (http://www.geomatics-group.co.uk). The EA's airborne-derived LiDAR data is provided in a variety of horizontal resolutions $(25 \mathrm{~cm}, 50 \mathrm{~cm}$, $1 \mathrm{~m}$ and $2 \mathrm{~m}$ ). However, the $1 \mathrm{~m}$ and $2 \mathrm{~m}$ resolution Lidar represents the most prevalent coverage. The LiDAR data is supplied in $2 \mathrm{~km}$ grid squares in ESRI's ASCII Grid format. LiDAR is flown mainly for undertaking flood-risk analyses and therefore, certain areas of the UK may not be covered at present by the surveys. However, for much of the fenlands, LiDAR data is currently available.

A LiDAR digital terrain model (DTM) of $1 \mathrm{~m}$ resolution was sourced for three case-study areas situated within the Cambridgeshire fens, including the Whittlesey, Warboys and Ely regions (Figure 1). A digital terrain model (DTM) was chosen over a digital surface model (DSM) as the former strips out buildings, trees and other such surface features, thus providing the user with a clearer picture of the underlying landscape. The $1 \mathrm{~m}$ resolution LiDAR provided by the EA has a vertical accuracy of approximately $18 \mathrm{~cm}$ and is therefore, much more able to represent the subtle topographical changes within the fenlands compared to the coarser OS-derived DTM's (Figure 3).

\section{Visualisation of the Fenland Landscape}

For the three case-study areas (Figure 1), LiDAR DTM's were processed from their original ASCII format to a raster format and mosaiced together in ESRI's ArcGIS v10.2 Geographical Information System software. Essentially, the raster data consists of $1 \mathrm{~m}$ resolution squares which each have a height attribute assigned to them, providing a height surface. Processed topographical raster data were then converted into the VSI format required by the Geovisionary program using Virtalis' dedicated VSI Converter software. Once imported into Geovisionary, this data provided a theoretical blank canvas height layer onto which can then be draped specific geospatial layers of the user's choice (e.g. Ordnance Survey base-mapping, geological and soil maps). The following sections will 
focus on the geomorphological, geological as well as the archaeological landforms that can be visualised within Geovisionary, providing a new and unseen perspective of the Fenland landscape.

The landscape analysis undertaken in this feature is related to ongoing research at the Cambridgeshire Geology Club (http://www.cambridgeshiregeologyclub.org) and their sub-group, the Cambridgeshire Geosites Team. The aim of the Cambs Geosites Team is to promote and identify areas of geological interest, recommending them for designation as locally or regionally important geological sites (RIGS). A particular interest of the team is to better identify the location of the fenedge and its inherent geological features, putting sites forward for RIGS designation and creating a 'fen-trail' scheme. The importance of high-resolution topographic mapping is therefore paramount for the landscape and geological evaluation helping to achieve this aim.

\subsection{Locating the fen-edge}

The fen-edge effectively represents the outer limit of fenland peat development and is considered to be representative of the land between the 5 and $10 \mathrm{~m}$ topographic OS contours. Passing through midLincolnshire and the east of Cambridgeshire, the fen-edge eventually meets the wash in northern Norfolk (Figure 1). The majority of the Fenland area is underlain by Jurassic clays, which have in geological time been more easily eroded compared to the surrounding chalk and limestone bedrock flanking the south and north-west, respectively. This erosion led to the formation of a basin, where subsequently many metres of superficial material have been deposited throughout the Quaternary period; through glacial activity as well as by many marine transgressions and regressions.

Geovisionary can provide the viewer with a 3D virtual fly-through of the Fen-edge (see: http://www.youtube.com/watch?v=Ak4j1pJEk0A), allowing it to be more easily visualised compared to conventional 2D mapping. The overlaying of geological and soils mapping is able to show the spatial distribution of peat deposits, the boundaries of which closely relate to the area between the 5 and10m contours. The topographic Islands (e.g. the Isle of Ely) of Jurassic clays and Cretaceous Greensand (Woburn Sands Formation) that have been more resistant to erosion and are sometimes capped with superficial glacial deposits can also be visualised. The terrain profile tool in Geovisionary allows the user to understand the relationship between the topography of these islands with that of the Fen basin (Figure 2). 
Figure 2 demonstrates a further useful function of GeoVisionary, whereby Google Sketchup models can be imported directly from Google Earth (http://earth.google.com) and be placed into the landscape view, here is shown Ely Cathedral (see: http://sketchup.google.com). This can give the user a further sense of spatial awareness and an appreciation of landscape magnitude. In other typical applications of this technology, the importing of 3D models can also help with visualising the impact of a structure, for example the location of proposed wind turbines, which can help to aid discussion between developers, planners and the general public.

\subsection{Buried channels}

The Fens contain a diverse range of geomorphological features derived from Pleistocene glaciations and the subsequent marine transgressions and regressions. Since this time, humans have drained the Fens to increase agricultural productivity. Large scale drainage began in the 1600's, although evidence for Roman-era drainage exists. This large-scale drainage, alongside increasing agricultural activity has resulted in the wastage of peat soils, as recorded by the Holme Fen Posts, where the surface of the peat has been lowered by $3 \mathrm{~m}$.

The loss of fenland peat and subsequent lowering of the overall ground surface has resulted in buried channels, (formed by historically active intertidal salt-marshes and relict river systems) to become raised above the surrounding ground level. These relict channels, known formally as roddons, form wonderful dendritic landforms, which, when rendered in a GIS system, almost represent works of art (Figure 4). However, these features are very subtle in their appearance, often with only 10 's $\mathrm{cm}$ height difference from the surrounding landscape. Figure 5 demonstrates this subtlety, with an approximate height difference of $50 \mathrm{~cm}$ compared to that of the surrounding landscape. Such small features would be invisible on courser DTMs, but LiDAR offers high-resolution topographic data suitable for such detailed landscape analysis. Much is still to be learned regarding the evolution and geomorphological history of roddons. However, this analysis can provide assistance in providing targeted, intrusive ground investigations to facilitate the stratigraphic understanding of these complex landforms.

\subsection{Mineral Extraction}

Extensive mineral extraction has taken place throughout much of the fen-edge area. The Whittlesey area contains numerous pits used to extract Oxford Clay for brick-making, chosen due to its relatively 
high organic content which aided firing. One of these pits at Must Farm (Figure 6) is of global importance, relating to the discovery of many fossilised marine vertebrates during excavations there, including; Plesiosaurs, Ichthyosaurs and marine crocodiles. To the west of Somersham, Cambridgeshire, the presence of many sand and gravel pits, which, when visualised in Geovisionary, assist the viewer in understanding the spread of sand and gravel deposits (Figure 7).

Many exhausted mineral extraction pits are subsequently remediated, offering new habitats for wildlife. Such sites are often used as geological teaching and geoconservation sites and represent many of the Sites of Special Scientific Interest (SSSI) in Cambridgeshire to date (e.g. Warboys Clay

Pit; Figure 8). The exposure of stratigraphic sections for teaching and general interest purposes being undertaken by geoconservation groups such as the Cambs Geosites Team. Therefore, the 3D visualisations of such sites could provide a means of establishing their landscape and geological context prior to fieldwork activities or their designation as RIGS sites. The use of smartphone and tablet viewable videos of such sites would make valuable education tools. Moreover, previously unrecognised stratigraphical exposures could be highlighted through the analysis of high-resolution topographic data allowing subsequent areas of geological interest to be preserved for the general public and specialist alike.

\subsection{Archaeological evaluation}

High-resolution LiDAR is an important and proven resource for archaeological evaluation. For example, a recent discovery of a Roman fortress and road near Hadrian's Wall in Cumbria was discovered following a re-visiting of historic LiDAR data. Therefore, as well as interpreting the geological features of a landscape, both human activity and associated archaeological landforms can also be visualised in the 3D environment of Geovisionary. Such data could then also be combined with other survey data, such as that from Ground Penetrating Radar (GPR) and Elecro-Magnetic Induction (EMI) scanners.

Archaeological sites can also tell us much about the geomorphological history of an area. For example, evidence of Roman fenland ports have been found many miles inland, revealing ancient shorelines. The Bronze Age Must Farm boat discoveries, now preserved at Flag Fen, are also suggestive of a very different fenland landscape from that of the modern day. 
It was whilst demonstrating the 3D Geovisionary model of the Whittlesey area that our attention was brought, by an archaeologist in the audience, to a series of Bronze Age barrows which were known to exist in an area just outside Peterborough. On inspection, these barrows were indeed revealed clearly by the LiDAR data; an example of the barrows morphology, together with a ring-ditch is shown in Figure 9.

\section{Summary}

The real power of 3D visualisation lies in the new dimension that it brings to landscape analysis. From our perspective, visualising landscapes in three dimensions is an excellent medium for engaging the general public in geological and geomorphological issues. The ability of 3D technology to integrate multiple geospatial layers, as well as 3D topographical models, enables a multi-disciplinary view of the landscape and will allow specialists to better target areas for field-studies. Ultimately, this will not only maximise the time spent undertaking relatively expensive fieldwork but it will also help promotion of cross-disciplinary discussion between a range of landscape specialists (e.g. archaeologists, geologists, soil scientists and geoarchaeologists). This technology is an additional toolset promoting the science of geology to the general public and the younger generation; specifically, those thinking of a future career in the geological sciences. Although this article has only discussed the Cambridgeshire Fenland landscape, many possibilities exist for the geological and geomorphological interpretation of many other areas of both the UK, and indeed internationally, where appropriate data is available.

\section{Suggestions for further reading}

Challis, K. 2006. Airborne Laser Altimetry in Alluviated Landscapes. Archaeological Prospection, v.13, pp. 103-127.

Chatwin, C.P. 1961. East Anglia and adjoining areas: $4^{\text {th }}$ Edition. British Regional Geology. Institute of Geological Sciences. HMSO, London.

Darby, H.C. 1983. The Changing Fenland. Cambridge University Press.

Mitasova, H., Harmon, R.S., Weaver, K.J., Lyons, N.J., Overton, M.F. 2012. Scientific visualization of landscapes and landforms. Geomorphology, vol. 137 (1), pp. 122-137. 
Smith, D.M., Zalasiewicz, J.A., Williams, M., Wilkinson, I.P., Redding, M., Begg, C. 2010. Holocene drainage systems of the English Fenland: roddons and their environmental significance. Proceedings of the Geologists Association, vol. 121 (3), pp. 256-269.

Sturt, F. 2006. Local knowledge is required: a rhythmananalytical approach to the late Mesolithic and early Neolithic of the East Anglian Fenland, UK. Journal of Maritime Archaeology, vol. 1, pp. 119-139.

West, R.G. 1991. On the origin of Grunty Fen and other landforms in southern Fenland, Cambridgeshire. Geological Magazine, vol. 3, pp. 257-262.

\section{Acknowledgements}

The authors and colleagues at Cranfield University are thankful to the Natural Environment Research Council's (NERC) Big-Data Capital Equipment Award (NE/LO12774/1) for 3D visualisation equipment and Geovisionary software; Environment Agency Geomatics Group for supplying high-resolution LiDAR data for the purposes of this research; lan Truckell and Jason Carvalho for their Geovisionary guidance and help with video production. 


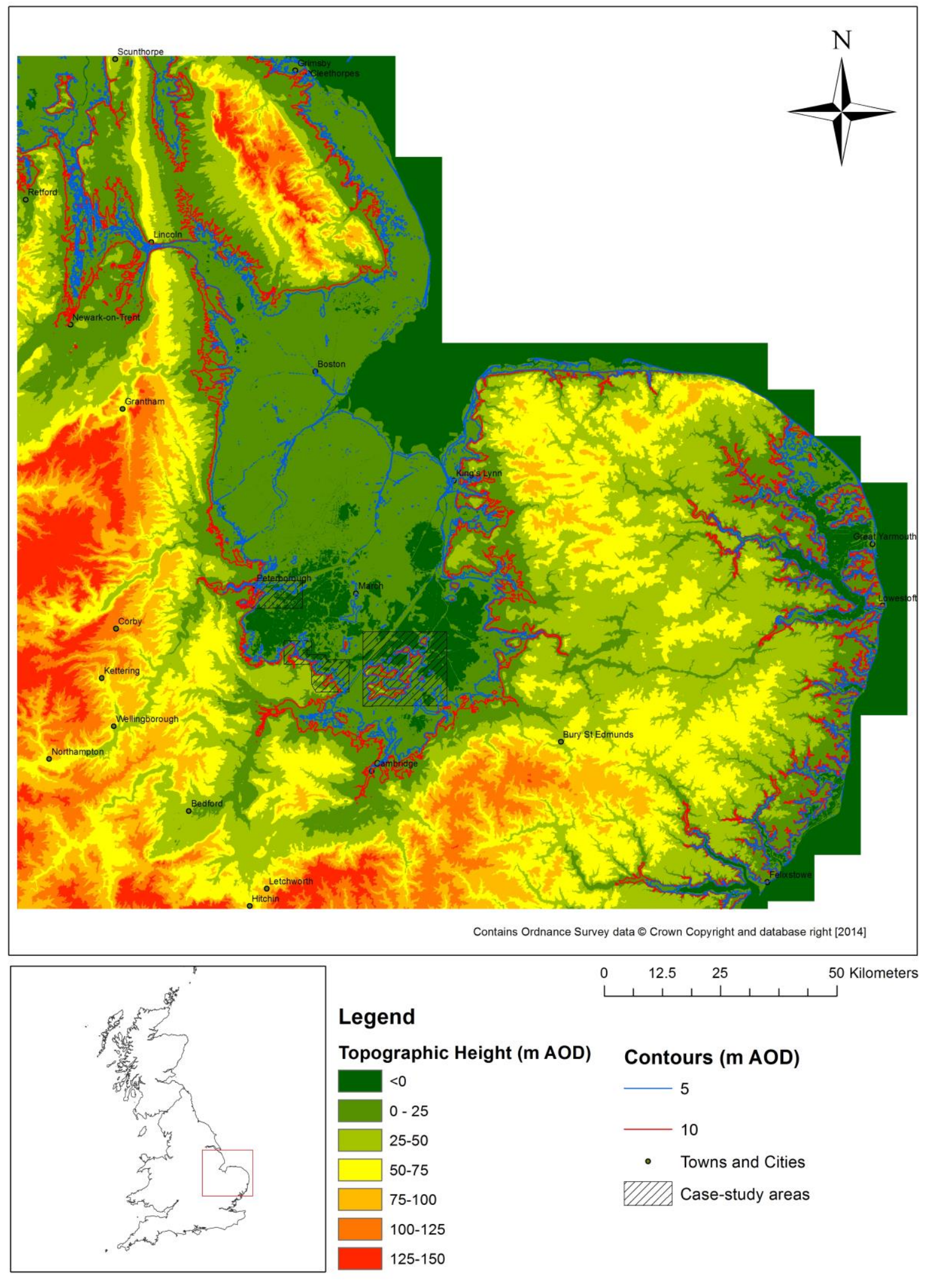

Figure 1: Overview map of the Fenland area, showing case-study areas and contours (5 and 10m AOD) representative of the Fen- edge. 


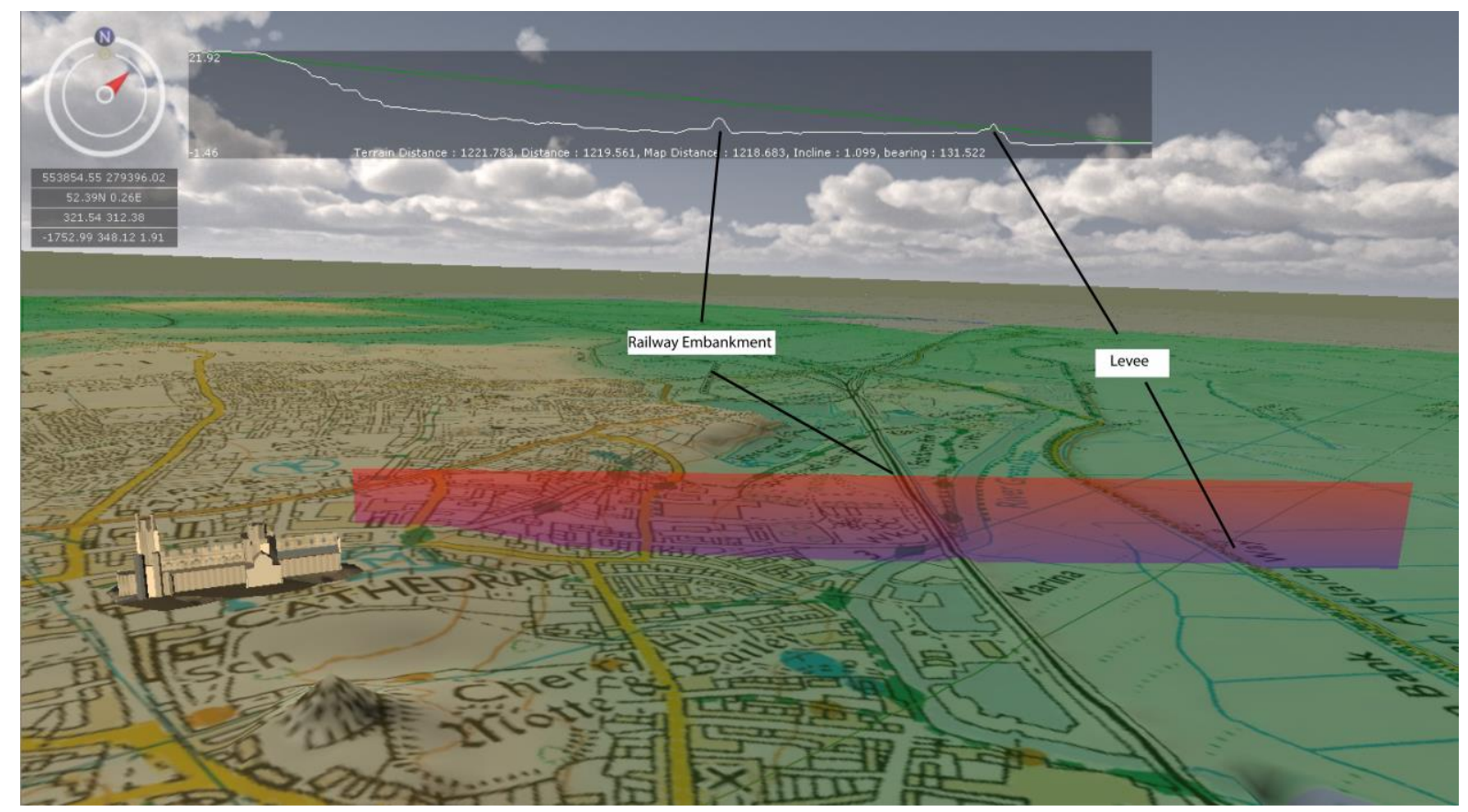

Figure 2: Geovisionary screen-grab showing example of the Terrain measurement and profile tool for analysing the fen-edge topography. Ely Cathedral model also shown (Contains Ordnance Survey data $\odot$ Crown Copyright and database right [2014]). 

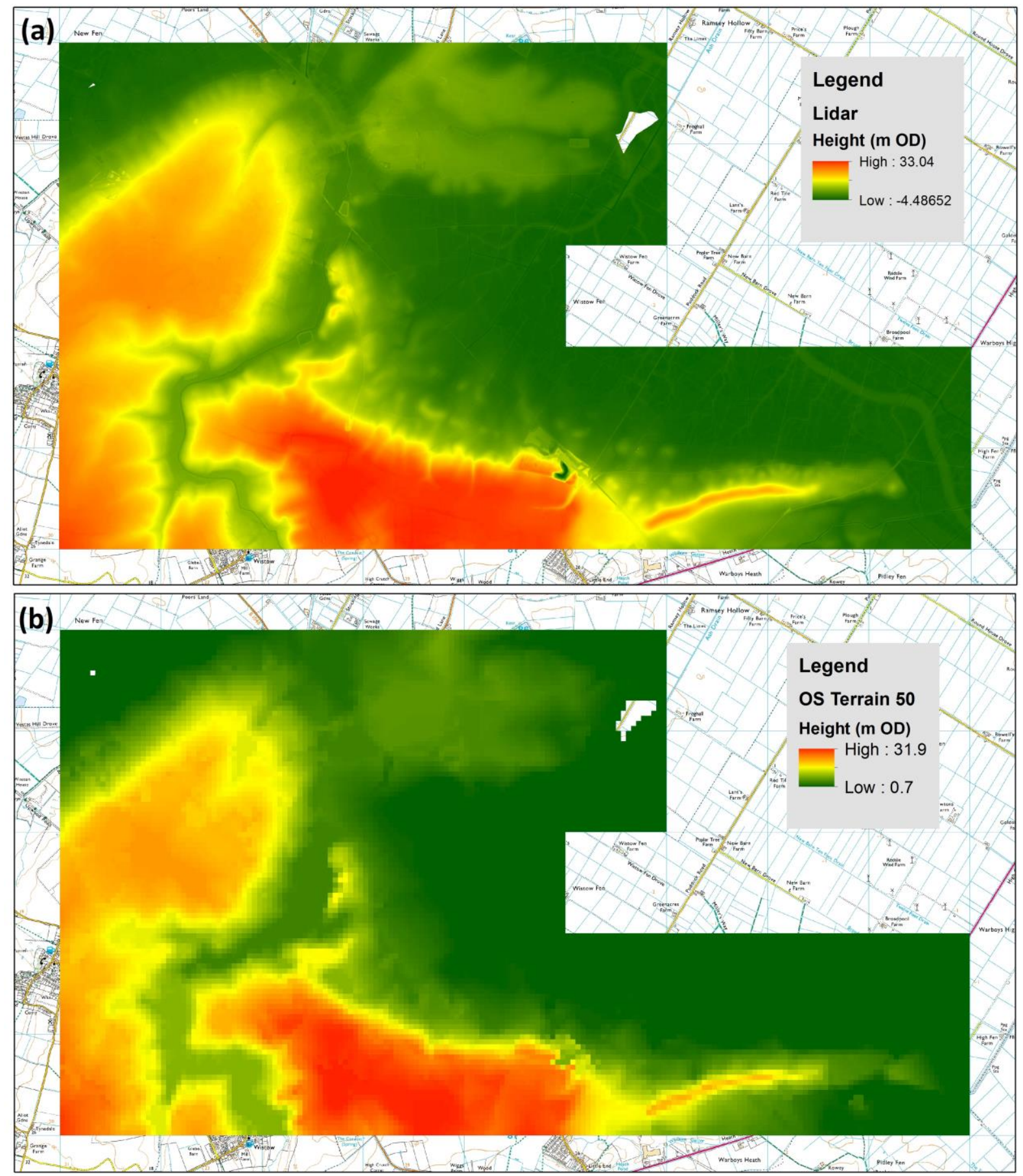

Contains Ordnance Survey data ๑ Crown Copyright and database right [2014]

Figure 3: Comparison of Environment Agency Geomatics Group airborne-derived 1m resolution LiDAR (a) with Ordnance Survey's $\left(50 \mathrm{~m}\right.$ resolution) Terrain $50^{\mathrm{TM}}$ (b) topographical digital terrain models. 


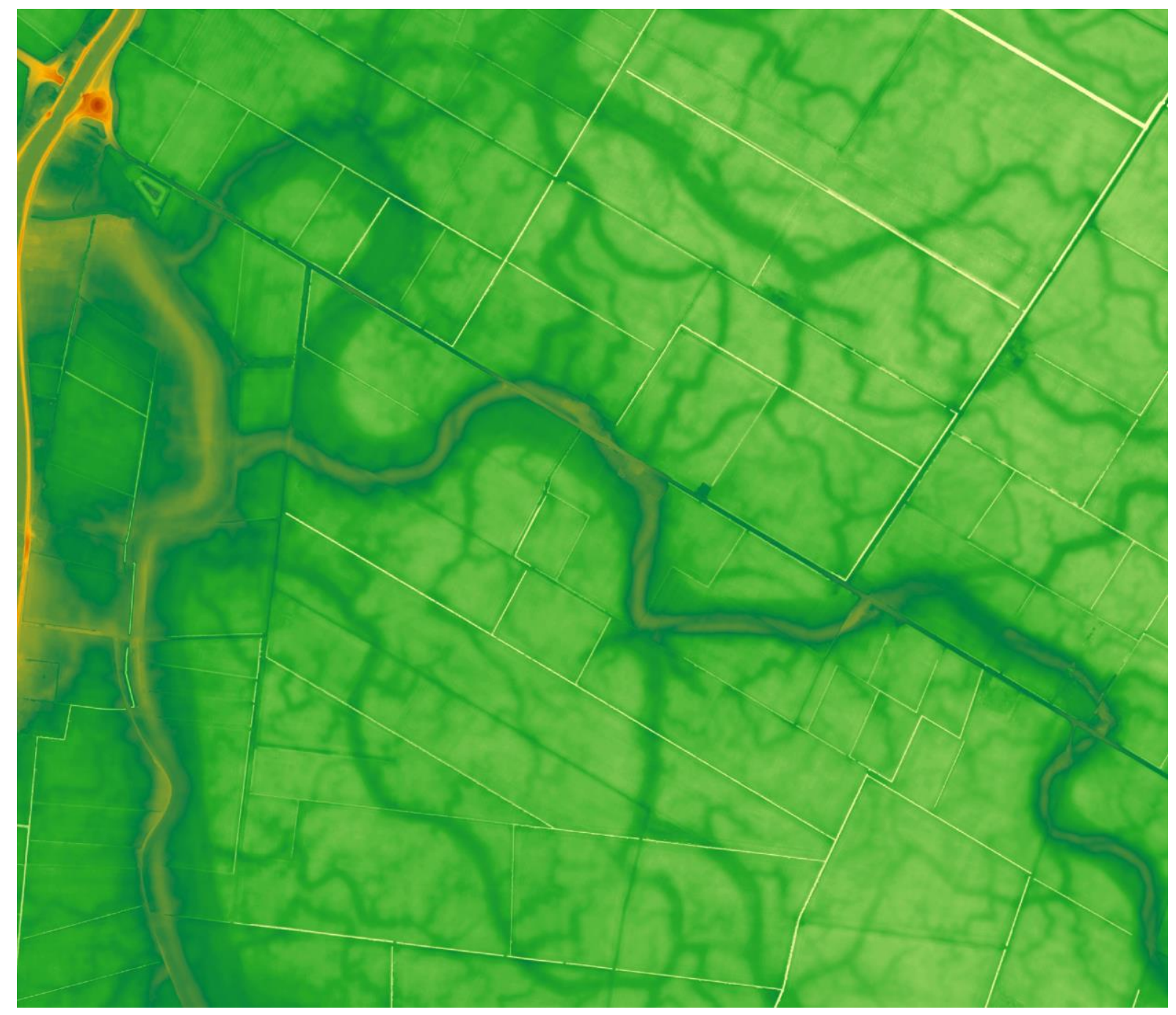

Figure 4: LiDAR (Environment Agency Geomatics) derived image of the relict creek networks around the Littleport area of Cambridgeshire. 


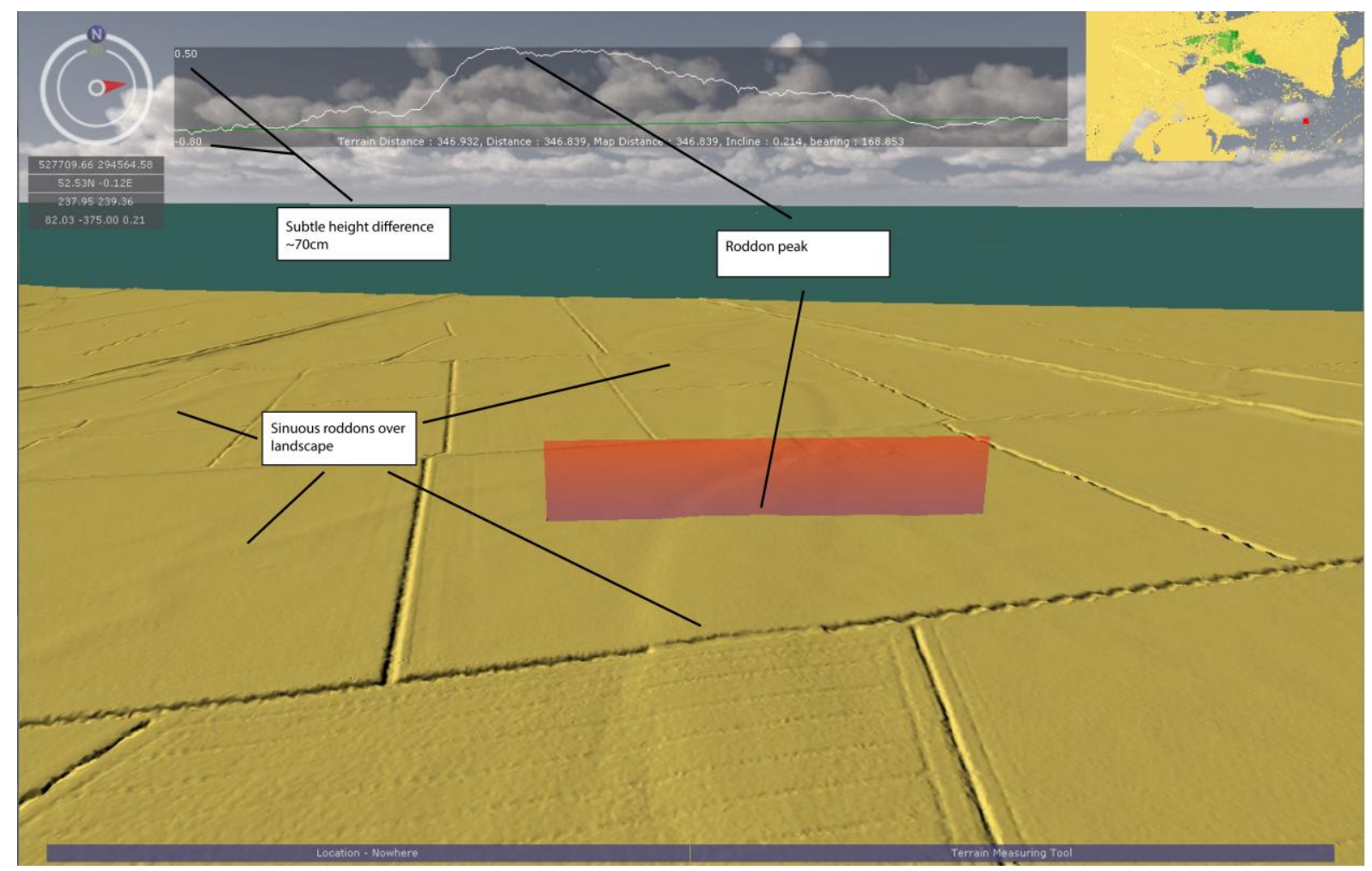

Figure 5: Digital screen-grab showing the subtle cross-section roddon profile.

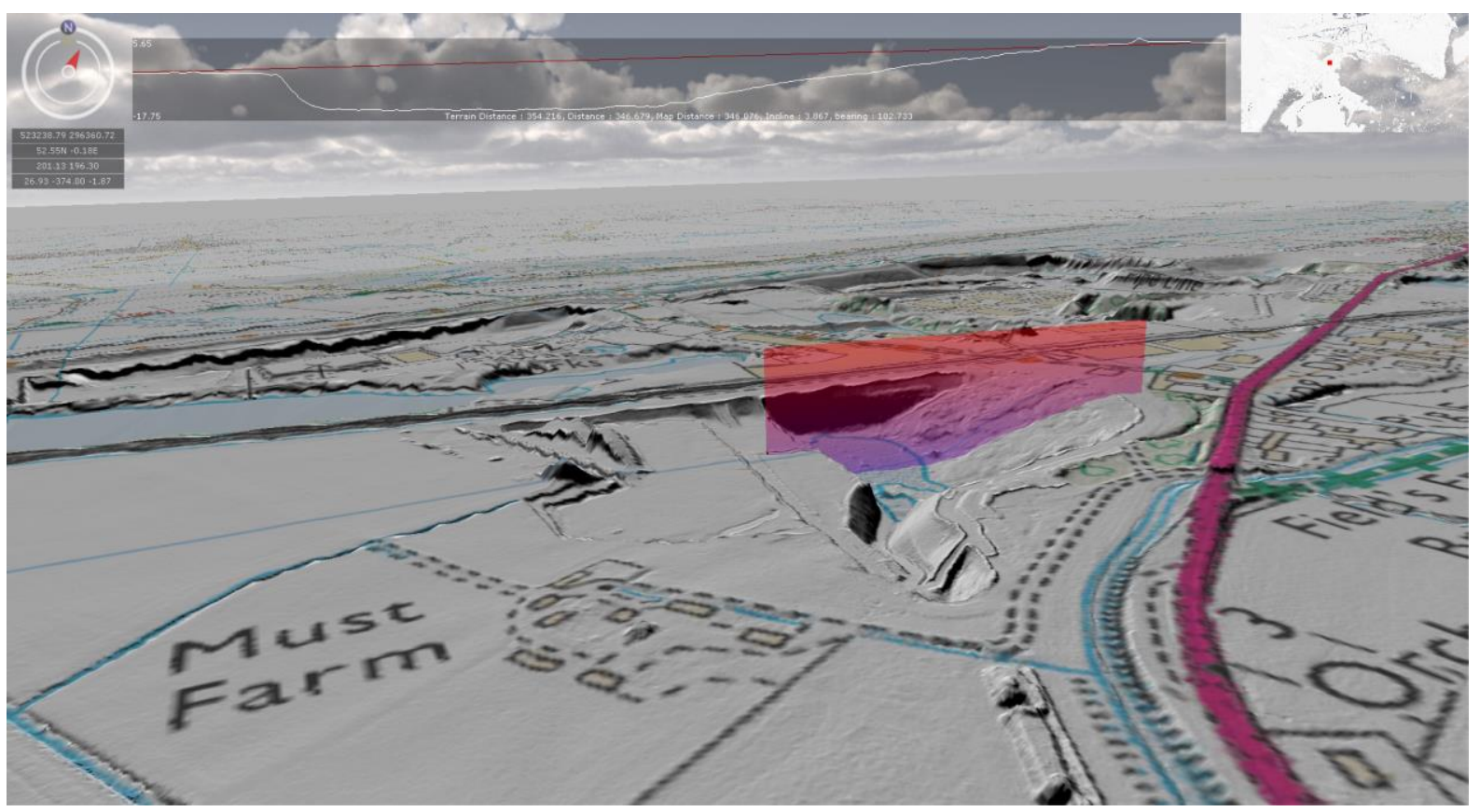

Figure 6: Digital screen-grab of Must Farm clay extraction pit with cross-sectional profile (Contains Ordnance Survey data (c) Crown Copyright and database right [2014]). 


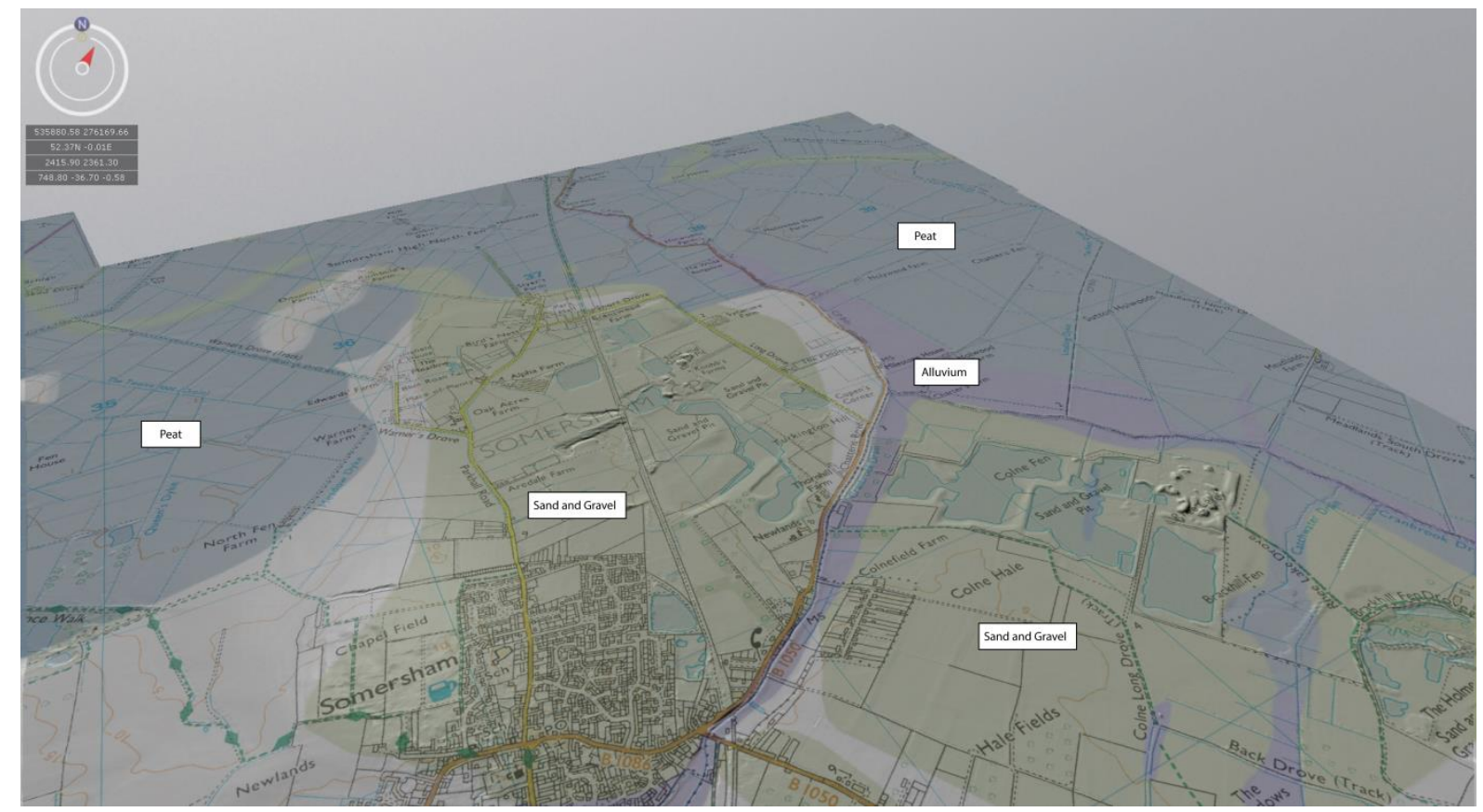

Figure 7: The distribution of sand and gravel extraction in relation to superficial sand and gravel deposits (BGS 1:50 000 [shapefile geospatial data] superficial geology supplied by Edina Geology Digimap Service; Contains Ordnance Survey data @ C Crown Copyright and database right [2014]).

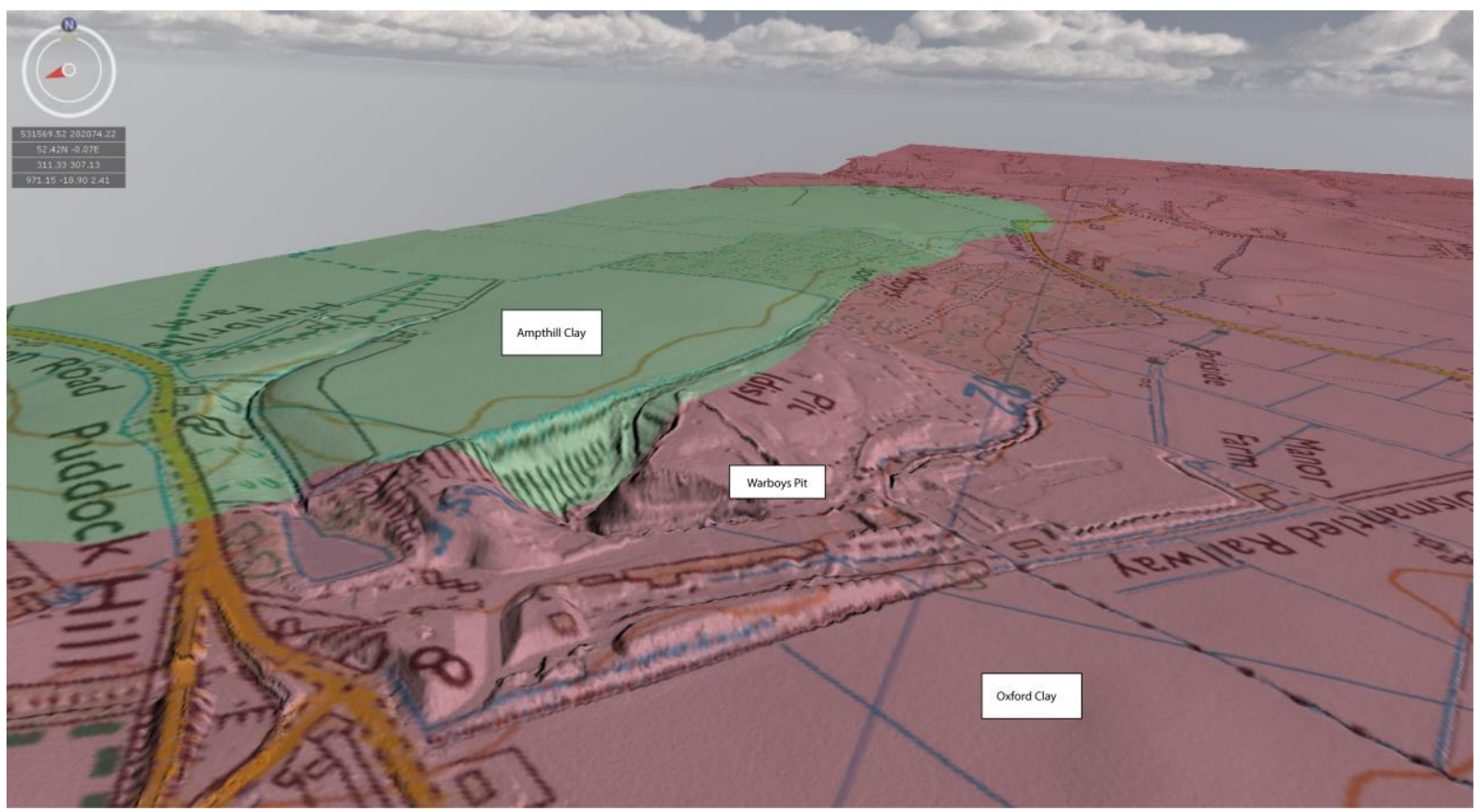

Figure 8: Digital screen-grab of Warboys Clay pit (Prior to remediation and infilling) showing its relation to the boundary of the Ampthill and Oxford Clay (BGS 1:50 000 [shapefile geospatial data] solid geology supplied by Edina Geology Digimap Service; Contains Ordnance Survey data @ Crown Copyright and database right [2014]) 


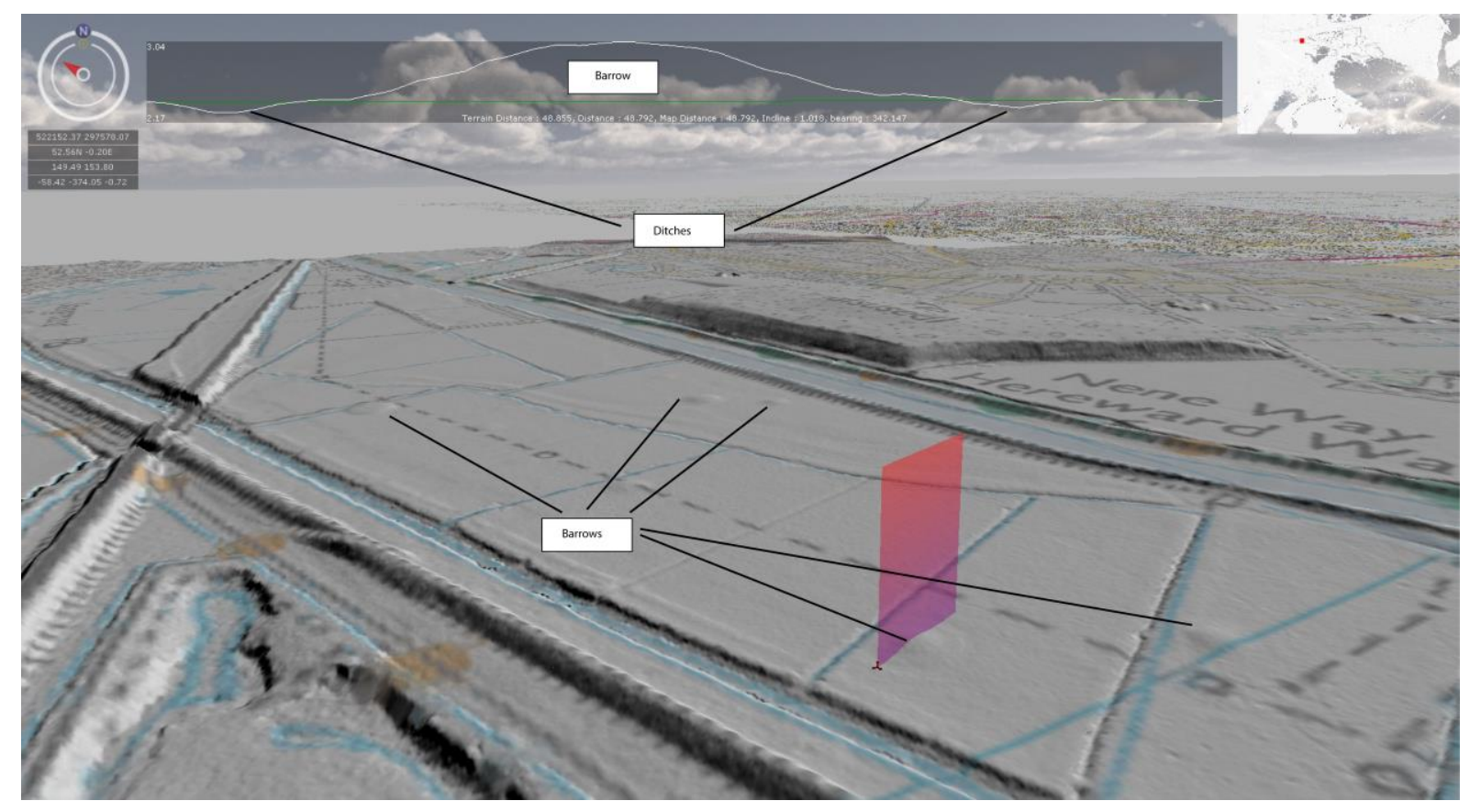

Figure 9: Digital screen-grab of Bronze Age barrows, near Whittlesey, Cambridgeshire (Contains Ordnance Survey data ( C Crown Copyright and database right [2014]). 